\title{
Overview: effects of radiation on the human body: acute and chronic sequelae in hematopoietic organs
}

\author{
Masao Tomonaga
}

Received: 30 September 2011/Revised: 15 February 2012/Accepted: 15 February 2012/Published online: 29 February 2012

(c) The Japanese Society of Hematology 2012

The Fukushima Dai-Ichi Nuclear Power Plant (NPP) accident occurred slightly more than 6 months ago in Japan. Approximately 770,000 terabecquerel of radioactive materials, including $\mathrm{I}^{131}, \mathrm{I}^{134}, \mathrm{Cs}^{134}$ and $\mathrm{Cs}^{137}$ were released following explosions at NPP, resulting the internal or external exposure to low-dose radiation in approximately two million Fukushima residents at accumulated annual doses ranging from less than 1.0 to $50 \mathrm{mSv}$. Air dose was reported to be highest during the first 2 weeks after the explosions. Human exposure to declining dose of radiation continues to occur as of the end of September 2011. General health examinations and estimates of total exposure dose for each resident, including several hundred thousand children, have been conducted since July. Preliminary results suggest that none of the subjects assessed were exposed to high doses, and that the thyroid exposure to radioactive iodine was below the governmental regulatory dose in 900 children tested.

Much lower doses of radiation were detected in a wider area, including the Kanto region of Japan, which includes the Tokyo metropolitan area, $300 \mathrm{~km}$ distant from the NPP. Food and tap water were contaminated with radioactive iodine and cesium, and seawater near the Pacific Coast and fishes caught in the vicinity of Fukushima were contaminated with these nuclides, as well as strontium. Central and local governments prohibited consumption and commercial sale of contaminated vegetables and fishes to minimize human exposure.

The accident at the Chernobyl nuclear power plant accident occurred 25 years ago, and released ten times as

M. Tomonaga $(\bowtie)$

Japanese Red Cross Nagasaki Atomic Bomb Hospital,

Nagasaki, Japan

e-mail:m-tomo@nagasaki-med.jrc.or.jp much radioactive material as were released from Fukushima over multiple European countries. A few million children in Ukraine, Belarus, and Russia were exposed to $\mathrm{Cs}^{137}$ and $\mathrm{I}^{131}$. The latter nuclides caused moderate exposure of the thyroid gland in many children, at doses exceeding $100 \mathrm{mSv}$ in this subpopulation. Over the past 25 years approximately 7,000 developed thyroid cancer, mainly papillary carcinoma and 20 children have died due to metastasis [1].

Twenty firemen at the Chernobyl plant who worked to extinguish fires during the accident were heavily exposed to sub-lethal or lethal dose of gamma and beta rays, either externally or internally, and all have subsequently died. Acute radiation syndrome (ASR) with severe bone marrow failure ensued, as evidenced by decline and disappearance of lymphocytes and neutrophils. Thirteen workers with severe bone marrow failure received allogeneic hematopoietic stem cell transplants in an attempt to save their lives, but these transplants were for the most part unsuccessful and 11 of the patients died due to the failure of multiple organ systems, such as skin, due to the extremely high dose of radiation. Only two have survived on achieving hematopoietic recovery [2].

The nuclear age began 66 years ago in 1945, when the Japanese cities Hiroshima and Nagasaki were devastated by the first and second military uses of atomic bombs. The fissile material in the Hiroshima bomb was uranium, while that in the Nagasaki bomb was plutonium. Approximately 200,000 residents in these two cities were killed instantaneously, or died within 3 months of the detonation, due to severe bodily injury caused by the extremely strong blast (pressure) or skin burns due to the heat of the explosion or subsequent fires, in addition to acute radiation injuries characterized by both bone marrow failure and destruction of intestinal lining. Approximately the same number of 
people survived the acute phase, and lived as atomic bomb survivors (hibakusha in Japanese). Hibakusha were exposed to a wide range of radiation doses, from as low as $1 \mathrm{mSv}$ to as high as $4,000-5,000 \mathrm{mSv}$, a dose considered to be LD50 for humans.

Among the most remarkable early events was triggering of three major types of human leukemia, namely chronic myelogenous (CML), acute myelogenous (AML), and acute lymphocytic leukemia (ALL), but not chronic lymphocytic leukemia (CLL) [3]. These began to occur as early as 3 years after the bombings. Similar trends in the time of leukemia induction were observed in the two cities, showing the reproducibility of leukemia induction by both uranium and plutonium bomb radiation. Such leukemias persisted for nearly 10 years, after which ALL and CML cases dropped rapidly around by 1960; in contrast, although AML declined gradually, it began to manifest again as MDS after 1980, when the survivors who were children aged less than 10 at the time of bombing became elderly [4], a trend that continues even now in 2011.

After the decline in leukemia incidence, solid cancers of various organs began to develop in hibakusha by around 1965, 20 years after the bombing, and since then have continued as the survivor age. Some survivors have developed more than one primary cancer in different organs due to systemic bodily exposure.

An official epidemiological study, the Life Span Study (LSS), has been conducted since 1950 by monitoring the LSS Cohort of approximately 100,000 survivors and estimating total exposure doses for individual cohort members. Gamma and neutron rays were the major components of the bombs' radiation. Overall results of statistic analysis revealed that leukemia induction was clearly dependent on exposure dose, as indicated by a linear-quadratic doseresponse curve, and a linear dose-response curve for solid cancers. For leukemias, the dose-response curve for excess cases became significant as low as $200 \mathrm{mSv}$ and solid cancers as $100 \mathrm{mSv}$. This dose of $100 \mathrm{mSv}$ has been adopted by the International Committee for Radiation Protection (ICRP) as the epidemiologically confirmed minimal cancer-induction dose [5]. The effects of dose ranges below $100 \mathrm{mSv}$ remain a matter of longstanding debate among radiation specialists. The ICRP has proposed a linear hypothesis that extends from $100 \mathrm{mSv}$ to zero. It suggests that lower doses are still dangerous, and should be taken into account when determining the regulatory minimal doses for evacuation from contaminated areas, and especially the protection of children from unnecessary exposure.

The large-scale radiation exposures at Chernobyl and the atomic bombing sites have provided us with a fundamental basis for considering the consequences of wholebody external and internal exposure, such as is now occurring in the area of Fukushima. Approximately 3,000 workers are engaged in containing and cleaning up after the NPP accident, and many have been exposed to higher doses of up to $600 \mathrm{mSv}$. General health surveys and cancer detection programs in particular will be needed for many years.

In this special review on the effects of radiation on the human body, four papers were invited to provide reviews of fundamental evidence for such effects and insights into what consequences may be suspected in the aftermath of the Fukushima accident. The authors are all highly qualified in this area, with expertise in radiation protection, a radiation epidemiology, hematology, and biology.

\section{References}

1. 25 Years after Chernobyl Accident, Safety for the Future, National Report of Ukraine, 2011.

2. Baranov A, Gale RP, Guskova A, et al. Bone marrow transplantation after Chernobyl nuclear accident. N Eng J Med. 1989;321: 205-12.

3. Preston DL, Kusumi S, Tomonaga M, et al. Cancer incidence in atomic bomb survivors. Part III. Leukemia, lymphoma, multiple myeloma, 1950-1987. Radiat Res. 1994;137(2 Suppl):S68-97.

4. Iwanaga M, Hsu WL, Soda M, et al. Risk of myelodysplastic syndromes in people exposed to ionizing radiation: a retrospective cohort study of Nagasaki atomic bomb survivors. J Clin Oncol. 2011;29:428-34.

5. ICRP Report 2007. 